\title{
Espais urbans i ideologia: el cas de la Plaça Reial de Barcelona (1822-1848)
}

\author{
JOAn MOLET
}

\section{Espais urbans i ideologia: el cas de la Plaça Reial de Barcelona} (1822-1848)

Resum

La Plaça Reial de Barcelona que avui coneixem és el resultat d'un procés que arrenca a finals del segle XVIII i pren forma a partir de 1822 amb la cessió del convent dels caputxins per construir-hi una plaça dedicada als herois de la Guerra del Francès. Però els diferents canvis de règim que se succeeixen al llarg del segle influencien decisivament en el concepte de la plaça, que tendeix a convertir-se en un espai més comercial que representatiu. Tot $i$ això, en alguns dels diferents projectes que es presenten en el concurs de 1848 , la idea patriòtica es manté amb força, però abordada des de diferents perspectives, des de la glorificació de l'Imperi Espanyol fins a la reivindicació catalanista. A partir de les diferents memòries dels projectes podrem analitzar els interessants programes iconogràfics proposats, la qual cosa ens permetrà mostrar l'ampli ventall d'opcions ideològiques dominants a Barcelona en el trànsit del Romanticisme al Realisme.

\section{Urban Spaces and Ideology: The Case of Barcelona's Plaça Reial Square (1822-1848)}

\section{Abstract}

Today's Plaça Reial square in Barcelona is the result of a process that started in the late eighteenth century, and took shape from 1822 when the Capuchin convent was relocated to the city in order to build a square dedicated to the heroes of the Napoleonic Wars. But various regime changes throughout the century decisively influenced the ideological concept of the square, which gradually became a commercial rather than a representative site. Nevertheless, some of the projects presented at the 1868 competition retained patriotic ideas, although they were considered in many different ways, from the glorification of the Spanish Empire to the vindication of the Catalan state. Based on several reports on these projects, we will analyse the interesting iconographic programmes proposed, allowing us to illustrate the wide range of ideologies present in Barcelona at the time between Romanticism and Realism.

MolET, J., «Espais urbans i ideologia: el cas de la Plaça Reial de Barcelona (1822-1848)», Acta/ Artis. Estudis d'Art Modern, 4-5, 2016-2017, pàgs. 151-161

PARAUles CLAU: Barcelona, urbanisme, ideologia, nacionalisme, Plaça Reial

KeYwoRDs: Barcelona, town planning, ideology, nationalism, «Plaça Reial» Square 
Moltes de les transformacions urbanístiques sofertes per la Barcelona vella durant la primera meitat del segle XIX tenen com a punt d'arrencada els diferents processos revolucionaris que es van viure a Espanya durant aquell convuls període. ${ }^{1}$ Entre les diferents propostes resulten particularment interessants les que es van fer a propòsit dels terrenys ocupats pel convent $i$ els horts dels caputxins a la part baixa de la Rambla, car presentaven un marcat esperit «patriòtic», que es va anar modificant amb el pas del temps des del constitucionalisme lliberal fins al nacionalisme català. El que ens proposem a continuació és l'estudi dels diferents projectes destinats a definir l'espai urbanístic que avui rep el nom de «Plaça Reial» per poder dibuixar aquesta evolució del concepte de patriotisme a la Barcelona del Romanticisme. ${ }^{2}$

\section{L'ORIGEN D'UNA PROPOSTA}

La idea de convertir aquest convent en un espai públic neix el 1793 quan Antonio Ricardos, capità general de Catalunya, d'ideologia lliberal, proposa traslladar els caputxins a Sant Pau del Camp, cenobi que ja havia estat exclaustrat, per poder crear una gran plaça al costat de la Rambla, ${ }^{3}$ idea que no comença a agafar cos fins al Trienni Liberal mitjançant el debat públic suscitat per l'aparició de diferents articles sobre aquest particular al Brusi.

El primer article apareix l'octubre de 1820 i justifica el trasllat per a aconseguir «el famoso sitio en que pudiera construirse la necesaria plaza mayor o de mercado público», tot buscant un espai per encabir «todos los puestos que ocupan desde la Boquería a Belén» i deixar lliures «los lados de la Rambla de S. Josef, que siempre están poco menos que impenetrables», ${ }^{4}$ donant resposta a un problema eminentment urbanístic. Dins d'aquest mateix esperit pràctic també podem situar la segona proposta, signada amb el pseudònim «El Aguijón», que, però, s'apartava del model tradicional de plaza mayor espanyola: «... la plaza en lugar de hacerse cuadrada fuese redonda o circular, disponiéndose a poder perfeccionarse más adelante por el estilo de la plaza del Vaticano de Roma». I demanava doblar l'extensió de l'espai, ocupant els terrenys de l'altre costat de la Rambla:

La Rambla a mi entender debía dividir por su centro esta gran plaza que facilmente pudiera construirse, tomando la mitad de ella de la huerta actual de capuchinos y la otra mitad de los colegios que igualmente vuelven a quedar de la nación según. ${ }^{5}$

Amb aquesta disposició es manté el caràcter útil de l'espai, que esdevé alhora monumental i grandiós perquè es basa en un model de prestigi.

1. Les vicissituds urbanístiques d'aquest període ja han estat ben exposades a GRAU, R.; LóPEZ, M., «El temps de la revolució urbanística», a GraU, R. (ed.), Exposició Universal de Barcelona 1888. Llibre del Centenari. Barcelona: L'Avenç, 1988, pàgs. 123-163.

2. L'anàlisi arquitectònica i urbanística ja fou duta a terme per Ignasi de Solà-Morales, per la qual cosa nosaltres ens centrarem en els aspectes ideològics; vegeu SolÀ-Morales, I. de; LóPEZ DE GUEREÑa CALDERón, A., La plaça Reial de Barcelona. De la utilidad y ornato público a la reforma urbana. Barcelona: ETSAB, 1982.

3. Esmenta per primera vegada aquest projecte Cèsar Martinell, tot i que no cita cap font; vegeu MARTINELL, C., «La Plaza Real. I. Su prehistoria accidentada», Destino, 1178, 1960, pàg. 18.

4. L'article, signat amb el pseudònim «El Espolín», dóna més detalls de com hauria de ser aquesta plaça: «Yo opino que esta debería quedar abierta por el frente de la Rambla y venderse a particulares el terreno sobrante del espacio demarcado para que construyesen edificios en los tres frentes restantes. [...] Para la construcción de los tres frentes convendría prescribirse una fachada igual, con elegantes y elevados pórticos»; "Noticias particulares de Barcelona», Diario de Barcelona, 289, 17 d'octubre de 1820, pàgs. 3341-3342.

5. «Noticias particulares de Barcelona», Diario de Barcelona, 328, 24 de novembre de 1820, pàg. 328. 


\section{UNA PLAÇA PATRIÒTICA}

No és fins al 1822, amb el nou Ajuntament constitucional, que la plaça projectada es revesteix d'un sentit «patriòtic». El mes de maig es nomena una comissió ad hoc, formada pels regidors Renart, Flaquer i Argelich, ${ }^{6}$ que ratifica la idea que la plaça s'estengui a ambdós costats de la Rambla i alhora decideix que ostenti el nom de «Plaza de las Cortes», ${ }^{7}$ sumant-se així a altres espais urbans projectats pel municipi que havien d'honorar els principis lliberals recollits en la Constitució de Cadis. ${ }^{8}$ Finalment, el 10 de desembre del mateix any ${ }^{9}$ Argelich presenta el projecte definitiu, ara denominat «Plaza de los Héroes Españoles» i que consta d'una planta, un alçat i d'un «Plan moral» i un «Plan físico». ${ }^{10}$

Segons el primer text, la funció moral de la plaça serà la d'«exaltar los ánimos de todos los españoles, y aún, si es dable, de todos los hombres, a la vista de los actos de virtud, beneficencia y amor a la Constitución de la Monarquía»" mitjançant un programa iconogràfic que preveu installar sobre els potents pilars que separen les arcades de la planta baixa estàtues de cos rodó que retratin «los héroes de la nación, por la humanidad, por la independencia y por la libertad». A sota de cadascuna d'elles, al nivell dels carcanyols, i també a la part alta dels edificis, ocupant tot el parament entre les finestres de l'àtic i adoptant la forma de fris, s'hi han d'adossar plafons en baix relleu que representin «las principales acciones heroicas de los mismos y demás hombres grandes que eternizaron el nombre español», plafons que també havien d'ocupar el mur interior de la porxada, sobre els accessos de les botigues. Tornem a la façana: sobre la llinda dels balcons es preveien uns medallons amb «los bustos de los semi-heroes» i a la cara exterior dels pilars, a un nivell més baix que els alt relleus, grans làpides amb «la lectura de la ley fundamental grabada» (illustració 1). ${ }^{12}$

Tot i que no s'havia concretat quins serien els quaranta-vuit herois, els cent semiherois o les cent quaranta-quatre escenes representades als relleus, és innegable el caràcter patriòtic lliberal que es vol imprimir a la plaça, com explicita el Diario Constitucional de Barcelona quan anuncia l'aprovació del projecte:

6. Arxiu Històric de la Ciutat de Barcelona (AHCB), Fons Municipals, Acords, 29 de maig de 1922, pàgs. 1023-1024.

7. «2. ${ }^{a}$ En atención á que en el terreno concedidio de Capuchinos no se puede construir sino la mitad de la plaza proyectada [...] conviene se suplique a las Cortes tengan á bien ceder para completar la Plaza el Colegio de San Buenaventura y la parte que se necesite del huerto de Trinitarios Descalzos", "3. ${ }^{\text {a }}$ Que toda vez que en la isla que se va á aumentar en las inmediación de la plaza de la Constitución está concedido por el Soberano Congreso el que la calle que resultará de aquella se denomine de Lacy y que el monumento del mismo se coloque en las nuevas obras de la dicha plaza de la Constitución, se titule la que se construya en la Rambla en los solares de Capuchinos y Colegio de San Buenaventura y demás, plaza de las Cortes»; AHCB, Fons Municipals, Acords, 4 de juny de 1822, pàgs. 1080-1082.

8. Entre aquestes actuacions previstes per l'Ajuntament destaquem la idea d'instal-lar un monument dedicat al general Lacy en l'ampliació de la plaça de Sant Jaume que s'hauria anomenat «Plaza de la Constitución». També és simptomàtica de l'esperit constitucionalista del Bienni Liberal la intenció d'acabar la catedral amb una façana neoclàssica decorada amb làpides amb textos de la Constitució i articles del Codi Civil, idea que, segons Carreras Candi, fou proposada el 1821 per Joan Estivill i parcialment duta a terme el 1823 quan l'Ajuntament va ordenar retirar les imatges religioses de les façanes dels edificis privats i substituir-les per aquestes làpides, que també foren instal-lades a tots els edificis públics de la ciutat; CARRERAs CANDI, F., Geografia general de Catalunya. Ciutat de Barcelona. Barcelona: Albert Martín, 1916, pàgs. 796-799.

9. AHCB, Fons municipals, Església, 16.1 CXVIII-3.

10. Segons Carreras Candi, aquest projecte fou publicat en forma de fulletó, del qual es conserva un exemplar a la sèrie d'Obreria de l'AHCB; CARRERAS CANDI, F., Geografia general..., pàg. 843, n. 2287. Tanmateix, el Diario Constitucional afirma que l'imprès esmentat es podia adquirir per setze rals a la Librería de Gaspar de la Baixada de la Presó; «Aviso», Diario Constitucional de Barcelona, 101, 11 d'abril de 1823, pàg. 4.

11. Argelich, J., Plan Moral, Plaza de los Héroes Españoles. Barcelona: Viuda e Hijos de D. Antonio Brusi, 1822, citat per CARreras CANDI, F., Geografia general..., pàg. 18.

12. «Proyecto para la construcción de una plaza patriótica en la Rambla terreno de Capuchinos y otros contiguos»; AHCB, Gràfics, Documents Visuals i Cartogràfics, núm. 3130. Aquest projecte ha estat publicat anteriorment per SuBIRANA ReBulL, R.M., Els orígens de la litografia a Catalunya: 1815-1825. Barcelona: Biblioteca de Catalunya, 1991. 


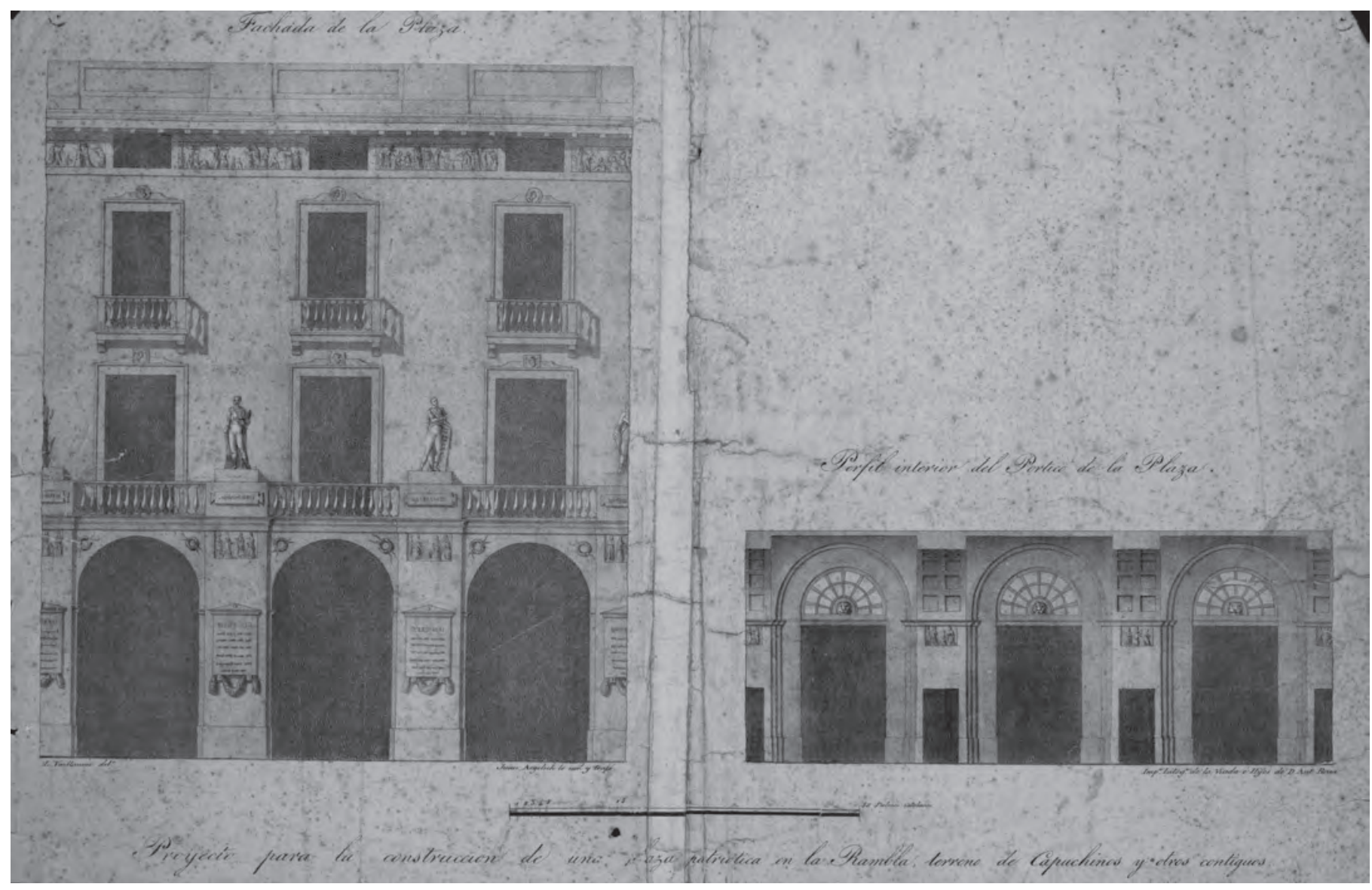

1. Louis

Vuillaume

(gravador) Josep

Argelich

(inventor)

Projecte per

a la construcció

d'una plaça

patriòtica

a la Rambla,

terreny

de Caputxins

$i$ altres contigus.

Façana

de la plaça i perfil interior del pòrtic de la plaça, 1822,

litografia. Arxiu

Històric de

la Ciutat

de Barcelona. la grandiosidad de esta obra, unida a los efectos morales que deben producir las estatuas, bajos relieves y demás adornos del arte [...] seran un eterno monumento de nuestras antiguas glorias que fomentará en nuestros pechos un noble entusiasmo por la conservación de nuestros fueros y libertades. ${ }^{13}$

\section{DE LA PLAÇA PATRIÒTICA AL PASSATGE COMERCIAL}

Aquest projecte, però, quedà aturat amb la restauració de l'absolutisme el mateix 1823 i la subsegüent restitució de la propietat del convent als religiosos. Va caldre esperar fins al 1836 i la Desamortització de Mendizábal perquè l'Ajuntament es tornés a plantejar la idea de la plaça. No obstant això, la titularitat del cenobi no fou concedida immediatament al municipi, sinó que fou transferida a l'Administración de Bienes Nacionales, la qual cosa esdevingué un nou escull.

Tot preveient una resolució favorable a la reclamació dels terrenys, ${ }^{14}$ la ciutat va decidir convocar el 1841 un concurs de projectes per erigir-hi un teatre de quatre mil localitats, però el

13. «Aviso», Diario Constitucional de Barcelona, 101, 11 d'abril de 1823, pàg. 4.

14. Actas de la Junta Censora convocada por el Excmo. Ayuntamiento con el objeto de examinar y calificar los proyectos presentados al mismo concurso para la formación de una plaza en el local que fue de los PP. Capuchinos de esta Ciudad $y$ memorias que acompañaron los planos publicados por voluntad de sus autores. Barcelona: Antonio Brusi, 1848, pàgs. 3-5. 
litigi es va anar dilatant, en part a causa de la negativa de la Real Academia de San Fernando a aprovar els dissenys presentats i en part a causa de la delicada situació del govern lliberal arran de l'esclat de la segona carlinada. Aquest impasse fou aprofitat el 1844 per l'arquitecte Francesc-Daniel Molina per lliurar dues ambicioses propostes (illlustració 2) en què, a més del teatre, s'hi preveia una moderna xarxa de «pasajes comerciales, alrededor de una plaza abierta», ${ }^{15}$ coberts amb vidre, que entroncaven amb el concepte eminentment comercial, tot i que actualitzat, dels projectes de 1820, però que tampoc no van ser realitzats perquè l'Ajuntament no disposà dels terrenys fins quatre anys més tard.

Finalment, el 1848 es reprèn un cop més el procés i en una data tan significativa com el 2 de maig es convoca un nou concurs, en l'anunci del qual s'obvia per complet el fervor patriòtic de vint-i-cinc anys enrere:

Habiendo el Excmo. Ayuntamiento acordado construir en el local que fue huerto y convento de los P.P. Capuchinos de la misma una plaza porticada que al mismo tiempo que sea un monumento que recuerde el buen gusto de la época presente tenga Barcelona una mejora de ornato y comodidad: invita al efecto esta corporación á los señores arquitectos de la Real Academia de San Fernando que gusten dar una prueba de sus conocimientos y afición a las mejoras urbanas de esta Capital, se sirvan presentar [...] el proyecto para la construcción de la mencionada plaza [...] y se advierte a dichos arquitectos que en la secretaría del Excmo. Ayuntamiento se darán todas las instrucciones y noticias que tal vez crean ser necesarias para la formación de su pensamiento. Barcelona, 2 de Mayo de 1848. El alcalde corregidor, D. Domingo Portefaix. ${ }^{16}$

Aquesta manca d'entusiasme en l'anunci municipal esdevé fins i tot desídia si tenim en compte que ni tan sols es va elaborar un programa, que únicament va ser redactat quan es van començar a sentir les queixes dels arquitectes. El text, molt breu, també és poc explícit, insisteix només en l'obligatorietat d'envoltar la plaça d'uns porxos i obvia qualsevol connotació simbòlica. Només en el quart paràgraf s'indica lacònicament:

En el centro de la plaza se levantará un Monumento u obelisco con la idea del objeto y nombre a quien se dedique para su futura memoria. Este nombre lo dará cada opositor, tomándolo de un hecho histórico o de una persona que haya dejado recuerdos memorables y heroicos en el país.

El «tema» de la plaça, doncs, esdevé gairebé irrellevant. ${ }^{17}$ Podem buscar l'explicació d'aquest desapassionament en un nou caire polític, arran de la majoria d'edat d'Isabel II (1844) i el seu suport als conservadors que elaboraren una nova constitució, cosa que va representar un veritable pas enrere, ja que es retornaven importants parcelles de poder a la monarquia $\mathrm{i}$ a l'Església, amb la intenció de compensar-la per les desamortitzacions. Per això ja no interessa rememorar els herois espanyols de la Guerra del Francès, car la seva memòria estava lligada a la Constitució de 1812 i al liberalisme que n'havia fet bandera. Per aquest motiu, l'Ajuntament prefereix deixar en mans dels mateixos concursants l'elecció del personatge o fet històric a commemorar, obligant-los a buscar un equilibri entre les pròpies conviccions i la ideologia del règim.

15. AHCB, Gràfics, Documents Visuals $i$ Cartogràfics, núm. 3094 i 3143.

16. Noticia histórica del concurso público abierto por el Excmo. Ayuntamiento de Barcelona para la presentación del proyecto de una plaza en el local que fué de los PP. Capuchinos de la misma Ciudad. Barcelona: Manuel Saurí, 1848, pàg. 55.

17. Coneixem el contingut del programa, atès que fou publicat per «varios arquitectos» al diari El Barcelonés per analitzar-lo críticament, paràgraf per paràgraf; VARIOS ARQUITECTOS, «Concurso público para la nueva plaza en el local que fue de Capuchinos», El Barcelonés, suplement del diari del 16 de juny de 1848, s/p. 


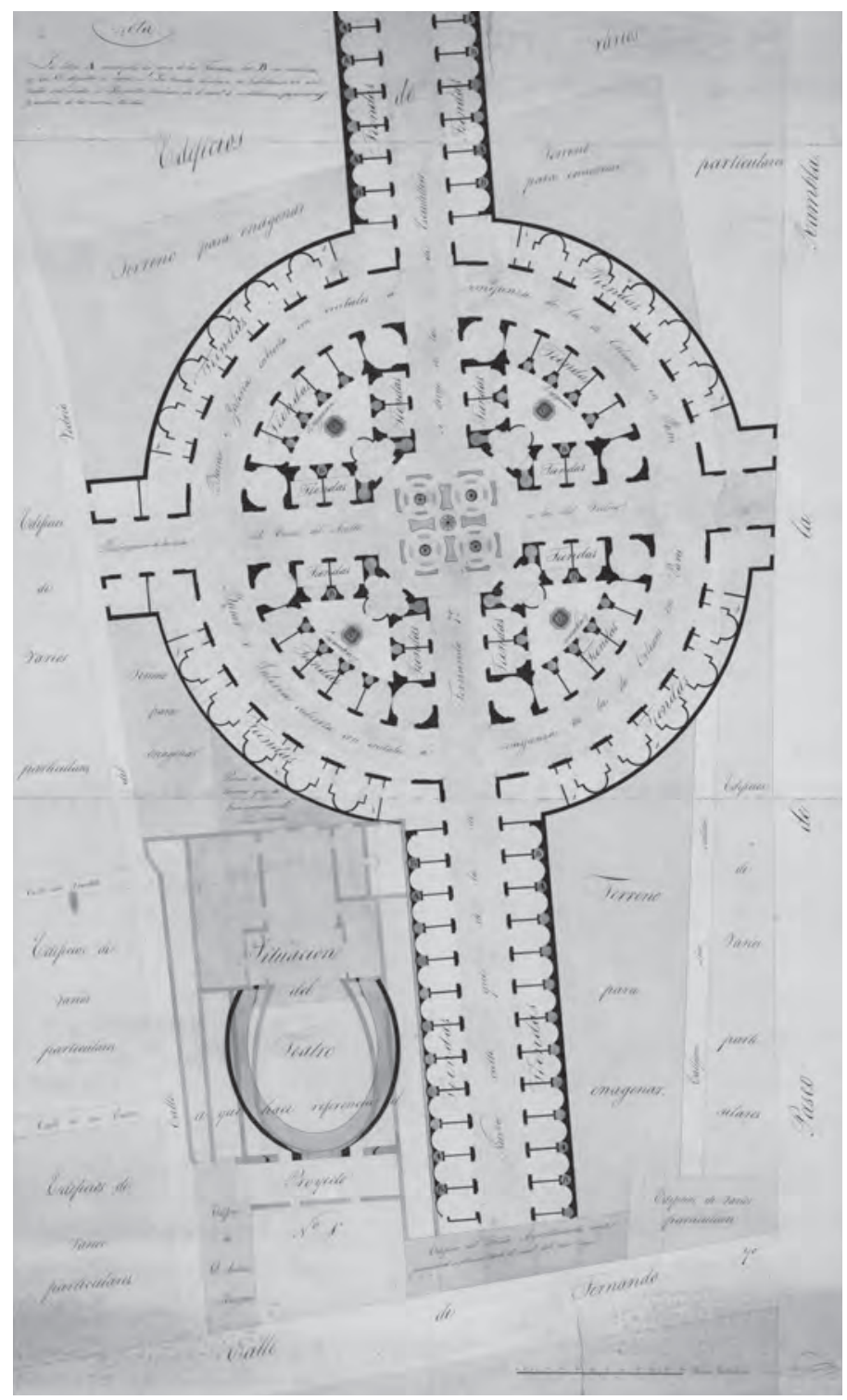

LES PROPOSTES DEL CONCURS

DE 1848 ENTRE LA BARCELONA

COMERCIAL, EL NACIONALISME

ESPANYOL I ELS IDEALS

DE LA RENAIXENÇA

Segons la documentació conservada es van presentar un total de quinze projectes, dels quals només coneixem l'autoria d'onze. ${ }^{18}$ Entre els signants figuren F.D. Molina i M. Garriga i Roca, que ja havien pres part en el concurs fallit de 1841, circumstància que els afavorí i els va permetre elaborar més d'una proposta. Garriga, per exemple, va tornar a lliurar un projecte dedicat a Isabel II i a la seva mare, Maria Cristina, elaborat el 1841 i en el qual ja incloïa un basar, a banda de quatre nous dissenys en què se centrava en la idea de crear espais comercials, tot eliminant qualsevol referència històrica.

Molina també segueix fidel a la seva idea comercial de la plaça, però la conjuga amb programes iconogràfics de més o menys volada, dos dels quals estan encaminats a l'exaltació de la nació espanyola: d'una banda, el que va obtenir el segon premi, en memòria de Blasco de Garay; ${ }^{19} \mathrm{i}$ de l'altra, el que commemora la figura dels Reis Catòlics com a artífexs de la unió dels regnes hispànics, que ostenta el nom de «Plaza de España» i en el qual

el monumento colocado en el centro de la plaza y en dirección a las cuatro calles, deberá recordar el

2. FrancescDaniel Molina Plànol del terreny de l'antic convent i hort dels Caputxins. Projecte de construcció d'una plaça amb galeries i un teatre. Zona de la Rambla, carrer del Vidre, Conde de Asalto i Ferran VII, 1844, plànol.

Arxiu Històric de la Ciutat de Barcelona. enlace de los dos monarcas, cuyas estatuas dándose la mano, serán coronadas por un genio que simbolizando la España, sostiene sobre sus cabezas la corona Real.

A partir d'aquest emblema central, la plaça havia d'esdevenir una gran lliçó d'història d'Espanya, amb dotze estàtues al seu voltant, «insiguiendo la idea de unión nacional», dedicades a «aquellos príncipes que con sus matrimonios, sus adquisiciones o sus conquistas, agregaron a la Corona de España, los dominios que han formado esta vasta monarquía», acompanyats de bustos als carcanyols del pòrtic, amb més personatges històrics, agrupats a l'entorn de quatre

18. Segons el costum de l'època, un cop designats els guanyadors del concurs de projectes es donava l'oportunitat a la resta de participants de donar a conèixer al públic les seves propostes; en el cas que ens ocupa, només quatre arquitectes -F.D. Molina, guanyador del primer i el segon premis, J.O. Mestres, guanyador del tercer; A. Rovira i Trias, i M. Garriga i Roca - van acceptar de desvelar els seus projectes; Actas de la Junta..., pàg. 13.

19. És inevitable relacionar aquest projecte amb la idea d'erigir un monument al mateix mariner inventor a la Plaça del Duc de Medinaceli, descartada a favor d'un personatge molt més en concordança amb els ideals de la Renaixença; vegeu Subirachs Burganya, J., «Una obra progressista a la Barcelona del segle XIx. El monument a Galceran Marquet», Espais, 28, 1991, pàgs. 45-49. 
temes: el Regne de Navarra, l'ocupació d'Itàlia, la conquesta d'Amèrica i la conquesta d'Àfrica. ${ }^{20}$ També fan esment d'aquests temes els noms dels carrers d'accés a la plaça: «Colón, Mendoza, Gran Capitán i Cisneros», o bé «Nuevo Mundo, África o Navarra, Granada e Italia», respectivament. Als extrems d'aquests carrers, Molina hi volia colllocar estàtues de «Carlos V, Felipe II, San Fernando y Jaime I», acompanyades dels relleus allusius a les batalles de «Pavia, San Quintín, la toma de Mallorca y la rendición de Sevilla». Com hem dit abans, era tota una lliçó d'història que posava l'èmfasi en la construcció de l'Imperi Espanyol, incloent-hi l'expansió catalana pel Mediterrani, per buscar la relació amb la ciutat de Barcelona, però també per destacar la contribució catalana a l'Espanya imperial.

Deixem de banda els altres dos dissenys de Molina, que reprendrem quan tractem de les propostes relacionades amb la història de Catalunya, i retornem a la plaça que Garriga volia dedicar a Isabel II per comprovar que en aquest cas el to del redactat i el mateix programa iconogràfic esdevenen molt més temperats, ja que només preveia «un sorprendente, elegante y rico monumento dedicado a perpetuar la memoria del feliz reinado de nuestra excelsa Reina», a més d'un «arco de triunfo que a la par que da entrada al bazar por la calle de Fernando, es otro testimonio del aprecio de los barceloneses hacia la augusta reina $D^{a}$ María Cristina» i l'homenatge «a la Serenísima Infanta doña Luisa Fernanda de Borbón», el nom de la qual havia d'ostentar «la otra puerta de entrada al bazar por la calle de Escudillers». ${ }^{21}$

En fort contrast amb el poc fervor patriòtic de Garriga destaca un projecte, malauradament d'autor desconegut, designat «Plaza de la Guerra de la Independencia» i que pel seu esperit, pel tema triat i per la seva intensitat simbòlica era el més proper a la idea inicial de la «Plaza de los Héroes Españoles». En la memòria adjunta s'afirma que s'ha triat aquest tema perquè és «el único que puede ser siempre grato a los partidos en que por desgracia está dividida España, [...] republicanos y progresistas, moderados y carlistas», perseguint una imatge d'Espanya unida per una causa comuna, dins la qual es vol recalcar «la gloriosa parte que les cúpo a los Catalanes en la defensa de su país pérfidamente invadido». De fet, la intenció és ressenyar l'aportació de tots els territoris a la Guerra del Francès, de manera que, a part de l'obligada referència al 2 de maig madrileny, simbolitzat per Daoiz i Velarde, també es rememora l'alçament asturià del 9 de maig, així com totes les batalles victorioses, de les quals s'inscriuen els noms dins de corones cíviques disposades cronològicament, acompanyades d'altres corones en què s'esmenten, una per una,

las antiguas provincias de España: Asturias, Galicia, Vascongadas, Castilla la Vieja, Castilla la Nueva, León, Extremadura, Andalucía, Murcia, Valencia, Cataluña, Aragón, Navarra é Islas Baleares y las de América Septentrional y América Meridional, para denotar que á la unidad de pensamiento de aquellas provincias [...] fue debido el triunfo de nuestra causa.

Dins de tot aquest desplegament destaca el nul protagonisme que s'atorga a un episodi cabdal com és la Constitució de 1812, sobre la qual es passa de puntetes mitjançant un baix relleu situat a un costat del pedestal del monument central de la plaça i que illustra «la apertura de las Cortes de Cádiz», a la qual acompanyen «la resistencia hecha por las Autoridades civiles de Barcelona á la prestación del juramento de fidelidad al rey intruso, José Bonaparte», el «alzamiento de las provincias» $\mathrm{i}$ «el sublime juramento de los soldados españoles en Lageland en Dinamarca, al mando del Marqués de la Romana». La resta d'aquest monument que pren la forma d'una columna rostral (illlustració 3) presenta un sòcol, amb sengles al-legories «de la Religión, de la Justicia de la Causa Española, de la Constancia y del Valor», i un grup escultòric principal al capdamunt, consistent en una allegoria de la

20. No podem reproduir la llarga llista de personatges retratats en aquests bustos; vegeu Actas de la junta..., pàgs. 46-50. 21. Ibidem, pàg. 64 . 


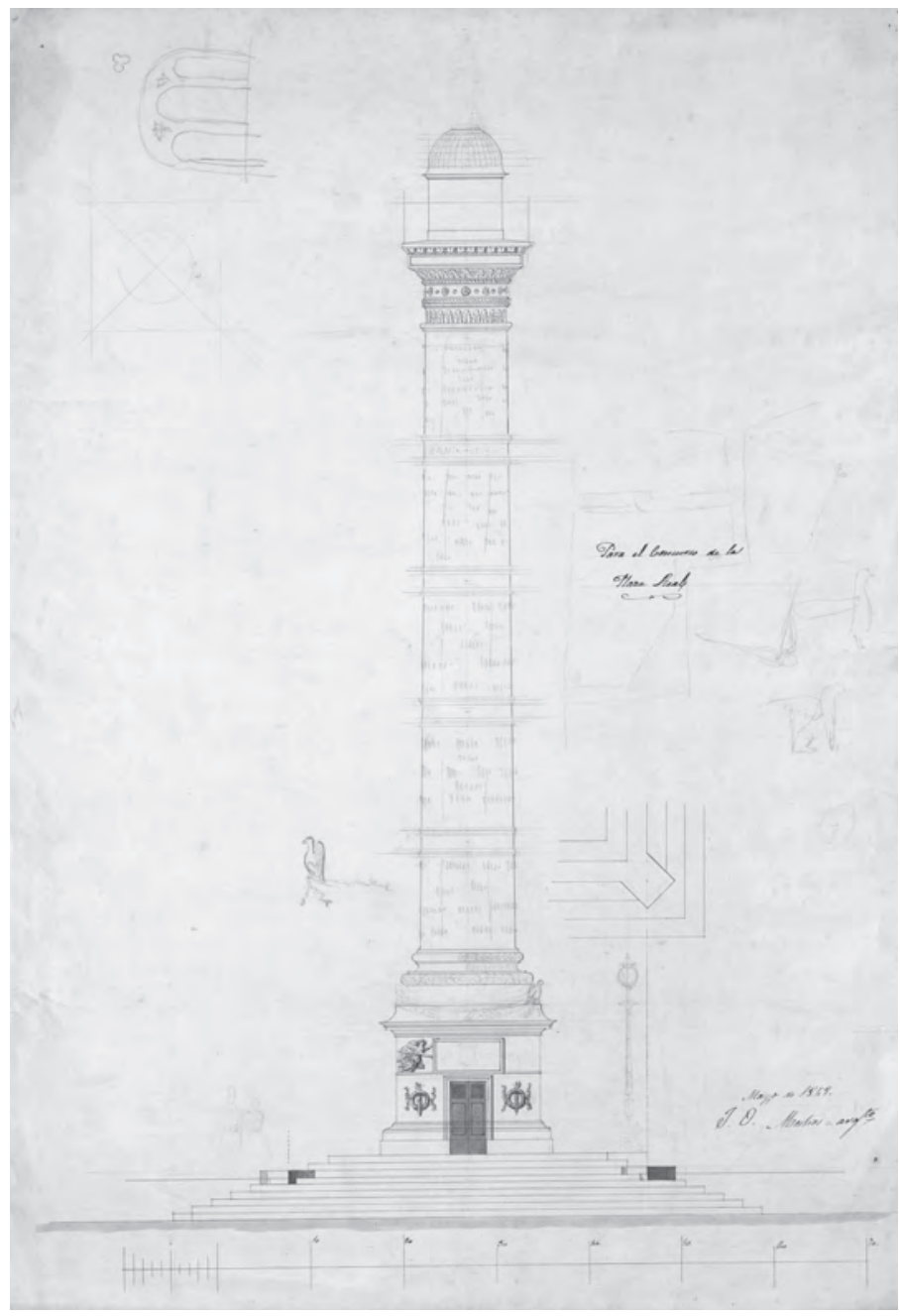

3. Josep-Oriol Mestres

Monument presentat al concurs de la Plaça Reial, possible avant-projecte de la columna rostral per al monument de la Plaça de la Guerra d'Independència, d'autor desconegut, 1848, plànol. Arxiu Històric de la Ciutat de Barcelona. ja que assenyala que el Consolat de Mar
España triunfante, ceñida en su sien una corona cívica, engalanada con el manto regio y apoyada sobre el escudo español, en actitud de reconocer en los designios de la Providencia el feliz desenlace de aquella asoladora guerra.

Per consegüent, la imatge que es dibuixa de la Guerra del Francès en aquest projecte de 1848 difereix en gran manera de la dibuixada en el projecte de 1822, en el qual la Constitució de 1812 esdevenia allò pel que havia pagat la pena sacrificar-se, mentre que ara el fruit d'aquesta lluita és l'Espanya unida, absolutista i catòlica de Ferran VII, reviscolada durant la Dècada Moderada. ${ }^{22}$

No obstant això, aquesta insistència en la unitat dels pobles d'Espanya es limita a les propostes que acabem d'examinar, car la resta se centren en els episodis propis de la història de Catalunya, això sí, dins del marc de la Corona d'Aragó. A més, tampoc no s'hi detecta la intensitat patriòtica que hem vist fins ara, atès que els programes iconogràfics o bé són molt simples o bé són descrits d'una manera molt succinta, a part que les referències històriques hi perden importància enfront dels motius relacionats, un cop més, amb el comerç i la indústria, com si fossin aquestes dues activitats les que realment es volen honorar com a motors de la prosperitat de Barcelona.

El projecte guanyador del concurs encaixa perfectament en aquests paràmetres; recordem que és una altra de les quatre propostes de Molina, que, a l'hora de ressenyar la seva «Plaza del Consulado» (de Mar), perd l'apassionament demostrat en la memòria del projecte dels Reis Catòlics, tot i que no perd el to altisonant quan assenyala que aquest codi marítim fou «el más grandioso monumento de la ilustración catalana, cuando todavía la Europa no había salido de las tinieblas de la barbarie». Però l'exaltació patriòtica només és un punt de partida,

nos recuerda nuestro dominio en el Mediterráneo en aquella época en que nuestro comercio llevaba al levante los productos de nuestra industria para cambiarlos con los ricos frutos del Oriente; llamaremos a las calles, del Comercio, de la Industria, de la Marina o del Mediterráneo.

És a dir, es passa per alt qualsevol connotació nacionalista de l'expansió catalana pel Mediterrani i es rebaixa fins i tot el que seria l'element central del projecte, que es redueix a una font (i no una estàtua) «alegórica al comercio, industria, agricultura, marina y al hecho de dar al mundo su código marítimo». Fins i tot les úniques estàtues previstes, adossades a la façana

22. La memòria d'aquest projecte és molt extensa i s'hi dóna nom fins i tot a les entrades dels edificis que envolten la plaça i a les fonts que l'ornamenten; pel que fa a la iconografia, vegeu Noticia histórica..., pàgs. 17-41. 
del cos central de l'edificació encarada a la Rambla, se centraven un cop més en «los hombres más eminentes y que más hayan descollado en el comercio, industria, agricultura, artes y marina en nuestro pais». ${ }^{23}$

En el seu darrer projecte Molina insisteix en l'expansió catalana pel Mediterrani, evocada en aquest cas mitjançant la figura de "Jaime I, el Conquistador», que donaria nom a la plaça i quedaria representat per una estàtua eqüestre, ubicada a un costat de l'accés principal des de la Rambla, en paral.lel a una altra estàtua similar amb la figura de «Dn. Pedro III que agregó la Sicilia a los estados de Aragón». Els noms dels quatre carrers d’accés, «Mallorca, Valencia, Murcia y Rosellón», reforçaven aquesta idea d'engrandiment del territori català i les estàtues de «nuestros ilustres Condes y antiguos Concelleres» haurien remarcat la pertinença dels dos herois a la Casa de Barcelona i, per tant, a la ciutat per a la qual es projectava la plaça. ${ }^{24}$

Josep Oriol Mestres, guanyador del tercer premi, també aprofità el recurs de relacionar l'expansió catalana pel Mediterrani amb el progrés econòmic de la Barcelona moderna i dedicà la plaça a Pere el Gran (illlustració 4), personatge que mereix ser honorat perquè era «amante del progresso científico, artístico, industrial y comercial», ${ }^{25}$ motiu pel qual Mestres proposà erigir

ocho estatuas de mármol blanco que rematan las cuatro puertas de entrada, las cuales representarían las ciencias, las artes, la industria, el comercio, la agricultura, la marina, el honor y la virtud: dotes que han guiado siempre a los catalanes en sus empresas científicas, artísticas, industriales o mercantiles, y que poseía en alto grado el gran Rey a quien dedico la plaza. ${ }^{26}$

És a dir, un altre cop s'evitava allludir a l'expansió pel Mediterrani com a gesta militar, obviant el paper dels almogàvers o el de Roger de Llúria, i es contemplava Catalunya només com a base del comerç i la indústria.

Insisteix en aquesta idea de relacionar la riquesa moderna de la ciutat amb el seu passat medieval, el projecte de «Plaza de los Condes de Barcelona», d'autor desconegut, que concentra el programa iconogràfic a les façanes dels edificis, prioritzant la del cos central avançat que mira a la Rambla, que s'havia de rematar amb un frontó amb rellotge al timpà, coronat per una allegoria de Barcelona, acompanyat de sengles representacions de l'arquitectura i l'escultura sobre els acroteris. En un nivell més baix, sobre la cornisa s'havien de disposar les estàtues dels comtes «con exclusión de los que por sus malos hechos se hicieron indignos de loa y recuerdo eternos ${ }^{27} \mathrm{i}$ sota la cornisa, un fris «que podrá contener algún hecho histórico de los de más nota». No es diu ni quins comtes ni quins fets històrics s'havien de rememorar, però sí que s'indica clarament la presència de les inevitables al-legories del comerç, la indústria, l'agricultura, la marina i les ciències ornamentant els pavellons d'entrada a la plaça.

L'única de les propostes relacionades amb la història de Catalunya que presenta un tarannà clarament catalanista és la presentada per Antoni Rovira i Trias, que apelllava clarament al patriotisme català a través del príncep de Viana. Recordar la figura del dissortat no esdevé una excusa més per lloar el caràcter emprenedor dels catalans, sinó que és un dels molts episodis amb què el nacionalisme català ha posat en relleu la necessitat de defensar la nostra idiosincràsia davant les intrigues de Castella, personificades en la figura de Juana Enríquez. Naturalment, aquest important canvi de registre es fa evident en el programa iconogràfic, desenvolupat a partir d'un monument central amb l'estàtua del príncep, que porta una espasa i una ploma, l'escut de Barcelona vora el cor i una corona partida als peus, travessada per una serp. Les quatre cares del pedestal ostenten relleus amb episodis històrics: l'empresonament del príncep, el

\footnotetext{
23. Actas de la junta..., pàgs. 28-29.

24. Noticia histórica..., pàgs. 83-84.

25. Actas de la junta..., pàg. 34 .

26. Mestres no dissenyà cap monument amb la figura del rei «por falta de tiempo»; Actas de la junta..., pàg. 38 .

27. Memoria histórica..., pàgs. 49-50.
} 


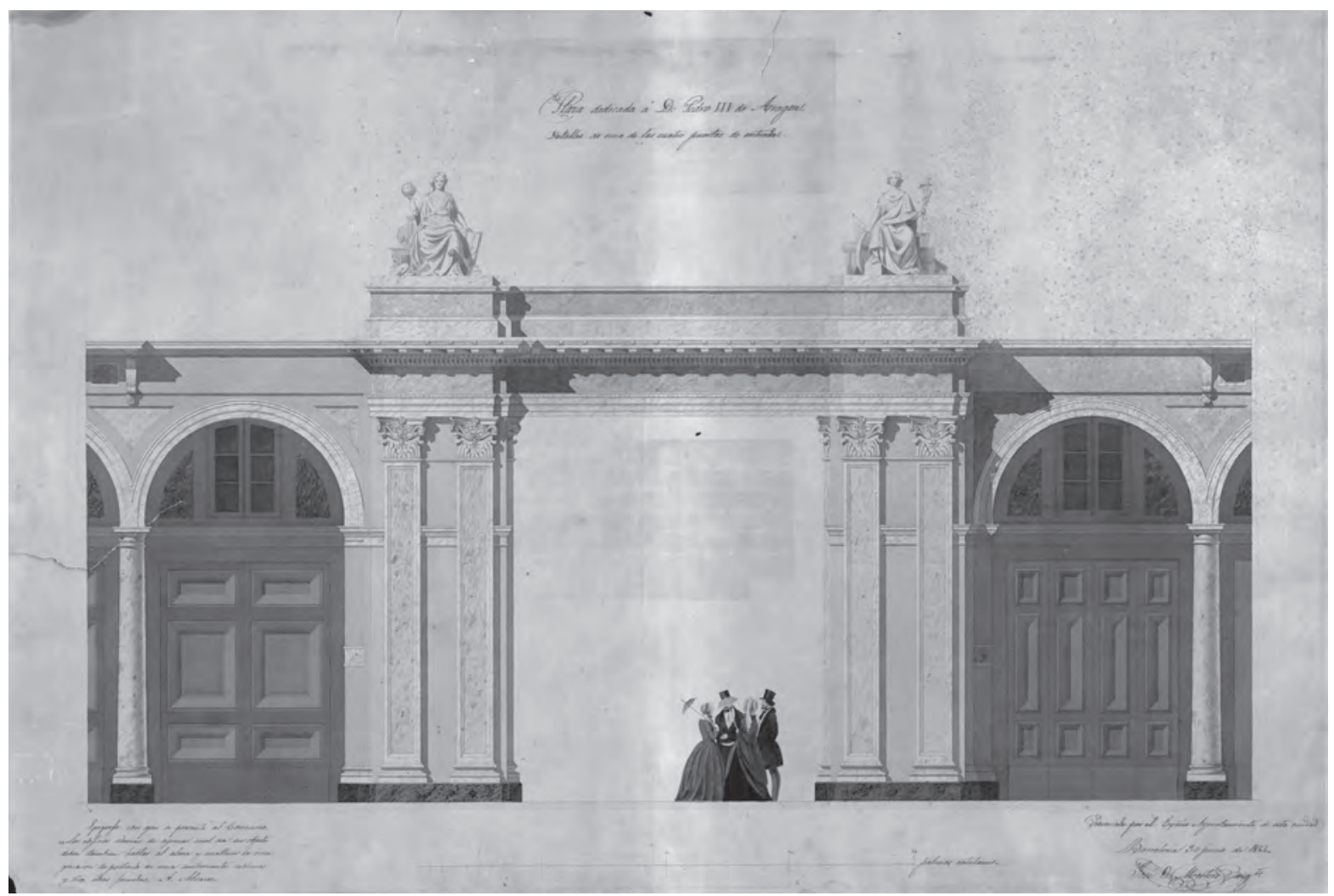

4. Josep-Oriol Mestres Plaça dedicada a Pere III d'Aragó. Detall d'una de les quatre portes d'entrada, 1854, dibuix aquarelllat. Còpia signada del projecte presentat al concurs de 1848, a la qual l'autor afegeix

«Premiado por el Excmo. Ayuntamiento de esta Ciudad». Arxiu Històric de la Ciutat de Barcelona. seu alliberament per part dels catalans capitanejats per Marimon, el setge a què fou sotmesa Barcelona per Joan II i els funerals del príncep en la nostra ciutat. Adossades a les façanes es proposen estàtues dels comtes de Barcelona i reis d'Aragó, situades en un lloc destacat les de Ramon Berenguer IV, Jaume I, Pere III i Pere IV, acompanyades dels escuts de les antigues possessions catalanes i de baixos relleus amb «la expresión de algunas de nuestras glorias». ${ }^{28}$

Amb aquest tema Rovira esdevé l'únic arquitecte que es posiciona clarament en l'àmbit ideològic de la Renaixença, car, més enllà de destacar la laboriositat dels catalans i la seva contribució a la grandesa d'Espanya, planteja un episodi històric que palesa un dels primers conflictes importants que enfronten el Principat amb Aragó i Castella, i remarca l'existència d'un tarannà propi de Catalunya dins la Corona d'Aragó i la seva determinació a defensar-lo.

\section{A MODE DE CONCLUSIÓ}

L'anàlisi iconogràfica dels diferents projectes de la Plaça Reial actual ens ha permès dibuixar l'evolució del concepte de patriotisme en l'àmbit català durant l'època del Romanticisme tot partint de l'exaltació del constitucionalisme de Cadis, és a dir, de l'Espanya liberal, per acabar apuntant un nacionalisme català que, impulsat pels intellectuals de la Renaixença, si bé ja és prou evident en el camp de la pintura, el 1848 encara no té prou força en l'àmbit de l'arquitec-

28. Actas de la junta..., pàgs. 55-58 


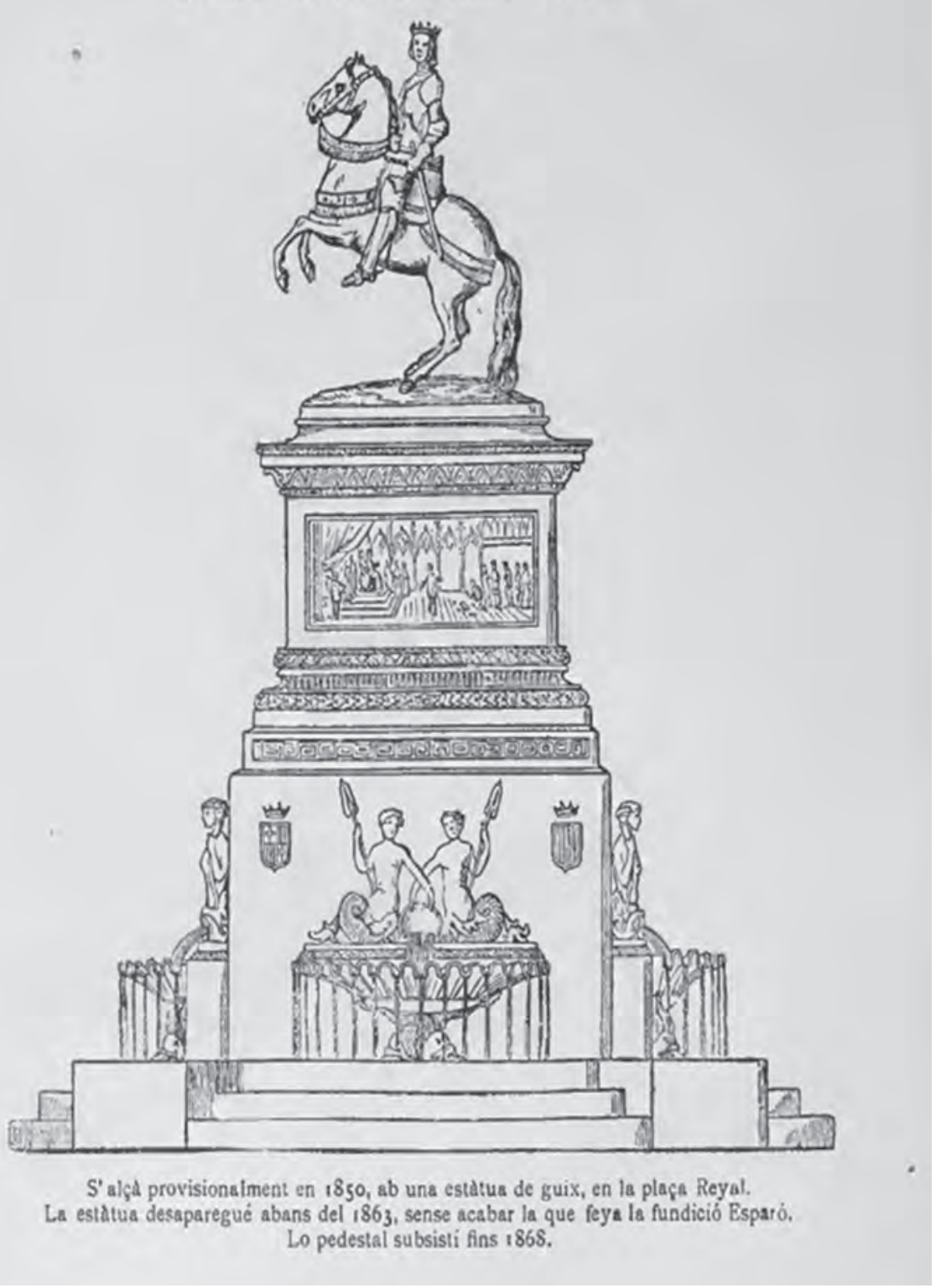

tura, de manera que, a excepció de Rovira i Trias, la resta de professionals opten encara per rememorar o bé episodis històrics poc compromesos o bé conceptes clau de l'ideari burgès com ara les bondats del comerç i la indústria. Per la seva banda, l'Ajuntament, format en bona part per aquesta burgesia industrial i financera, però amb molt poc marge de maniobra respecte al govern espanyol, es decanta per una solució de compromís quan al final de tot el procés decideix triar el projecte arquitectònic que al-ludeix al Consolat de Mar, que recalca la nostra gran contribució al dret marítim i, per tant, al desenvolupament del comerç, però que inclou una estàtua eqüestre de Ferran el Catòlic (illlustració 5), personatge que representa l'aliança entre els regnes d'Aragó i Castella i, per tant, el lligam entre Catalunya i Espanya.

Amb tot, les vicissituds del monument a Ferran II, comparables amb les dels nonats monuments al general Lacy o a Blasco de Garay, illlustren molt bé aquest tomb ideològic i aquest despertament del nacionalisme català que anirà substituint els Mercuris i les Minerves pels Jaumes I i els Fivellers. 